\title{
Fetal Pain, Abortion, Viability and the Constitution
}

\section{Citation}

I. Glenn Cohen \& Sadath Sayeed, Fetal Pain, Abortion, Viability and the Constitution, 39 J.L. Med. \& Ethics 235 (2011).

\section{Published Version}

http://onlinelibrary.wiley.com/doi/10.1111/j.1748-720X.2011.00592.x/pdf

\section{Permanent link}

http://nrs.harvard.edu/urn-3:HUL.InstRepos:12025606

\section{Terms of Use}

This article was downloaded from Harvard University's DASH repository, and is made available under the terms and conditions applicable to Open Access Policy Articles, as set forth at http:// nrs.harvard.edu/urn-3:HUL.InstRepos:dash.current.terms-of-use\#OAP

\section{Share Your Story}

The Harvard community has made this article openly available.

Please share how this access benefits you. Submit a story.

\section{Accessibility}




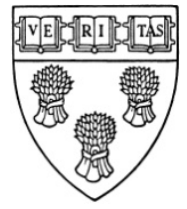

Harvard Law School

Public Law \& Legal Theory Working Paper Series

Paper No. 11-26

\title{
"Fetal Pain, Abortion, Viability and the Constitution"
}

\author{
I. Glenn Cohen \\ Harvard Law School
}

This paper can be downloaded without charge from the Social Science

Research Network (SSRN) electronic library. 


\title{
Fetal Pain, Abortion, Viability and the Constitution
}

\author{
I. Glenn Cohen and Sadath Sayeed
}

Forthcoming, 39 The Journal of Law, Medicine and Ethics (April/May 2011). The definitive version will be available at www.blackwell-synergy.com.

\section{BIOS:}

I. Glenn Cohen, J.D., is an Assistant Professor and Co-Director of the Petrie-Flom Center for Health Law Policy, Biotechnology, and Bioethics at Harvard Law School.

Sadath Sayeed, J.D., M.D., is an Instructor in the Division of Medical Ethics of the Department of Global Health and Social Medicine at Harvard Medical School and a Staff Neonatologist at Children's Hospital Boston.

On April 13, 2010, Nebraska enacted a new state ban on abortion in the PainCapable Unborn Child Protection Act that has caught the attention of many on both sides of the abortion debate, ${ }^{1}$ and has inspired other states to attempt similar measures. ${ }^{2}$ The statute requires the referring or abortion-providing physician to make a "determination of the probable postfertilization age of the unborn child" (defined as, "the age of the unborn child as calculated from the fertilization of the human ovum") and makes it illegal to induce or attempt to perform or induce an abortion upon a woman when the "probable postfertilization age" of the fetus is "twenty or more weeks" unless the doctor determines in "reasonable medical judgment (1) she has a condition which so complicates her medical condition as to necessitate the abortion of her pregnancy to avert her death or to avert serious risk of substantial and irreversible physical impairment of a major bodily function or (2) it is necessary to preserve the life of an unborn child."3 It also offers a civil action to the father of the unborn child, its grandparents, or the woman for "knowing or reckless violation of the act for actual damages," as well as providing for injunctive relief. $^{4}$

The Act offers a new theory to make these abortions illegal: fetal pain. As its legislative findings the bill states that:

(1) At least by twenty weeks after fertilization there is substantial evidence that an unborn child has the physical structures necessary to experience pain; (2) There is substantial evidence that, by twenty weeks after fertilization, unborn children seek to evade certain stimuli in a manner in which in an infant or an adult would be interpreted as a response to pain; (3) Anesthesia is routinely administered to unborn children who have developed twenty weeks or more past fertilization who undergo prenatal surgery; (4) Even before twenty weeks after fertilization, unborn children have been observed to exhibit hormonal stress responses to painful stimuli. Such responses were reduced when pain medication was administered directly to such unborn children; and (5) It is the purpose of the State of Nebraska to assert a compelling state interest in protecting the lives of unborn children from 
the stage at which substantial medical evidence indicates that they are capable of feeling pain. ${ }^{5}$

The Act went into effect on October 15, 2010, and potentially provides judges already inclined against the abortion right a new doctrinal basis to bypass or supplant existing constitutional precedent. It differs from previous abortion laws that have made reference to fetal pain, such as the "partial birth abortion" ban at issue in Gonzales v. Carhart, in that it seeks to prohibit any abortion procedure on the ground of fetal pain, rather than restrict women to particular forms of abortion less likely to cause fetal pain. ${ }^{7}$ Proponents of the law perhaps anticipated an immediate legal challenge, but may also hope it could ultimately make it to the Supreme Court where it would provide the Roberts' Court an opportunity to rewrite the Court's abortion jurisprudence.

In this paper, we briefly review the existing constitutional focus on - and problems with - the viability construct and we further argue that although the question is a novel one with few clear precedents, the best reading of the existing Supreme Court case law is that even if fetal pain exists at 20 weeks postfertilization - itself a speculative claim - that should not suffice to make this new statutory prohibition on abortion constitutional.

\section{Existing Constitutional Doctrine and the Trouble with Viability}

To appreciate the novelty of and challenges posed by the Nebraska statute, it is useful first to understand the existing doctrinal focus on viability. Although Roe v. Wade is commonly associated with the trimester framework it introduced, it is also the origin of the Supreme Court's tying of the state's ability to prohibit abortion to the viability of the fetus:

With respect to the State's important and legitimate interest in potential life, the 'compelling' point is at viability. This is so because the fetus then presumably has the capability of meaningful life outside the mother's womb. State regulation protective of fetal life after viability thus has both logical and biological justifications. If the State is interested in protecting fetal life after viability, it may go so far as to proscribe abortion during that period, except when it is necessary to preserve the life or health of the mother. ${ }^{8}$

As Justice O'Connor made explicit in her 1983 dissenting opinion in City of Akron v. Akron Center for Reproductive Health, Inc., under this rationale "[a]s medical science becomes better able to provide for the separate existence of the fetus, the point of viability is moved further back toward conception," such that, with each advancement in neonatology that pushes viability earlier in gestation the set of abortions the state can constitutionally prohibit grows. ${ }^{9}$ In its 1992 decision in Planned Parenthood v. Casey, the Supreme Court expressly rejected the trimester framework in favor of treating viability as the primary dividing line, intoning that "there is no line other than viability which is more workable," as the point at which the state's interest in preserving fetal life becomes compelling and overrides the mother's interest in procuring an abortion. ${ }^{10}$ The court also 
acknowledged that the viability line then stood at 23 or 24 weeks by last menstrual period (LMP). ${ }^{11}$

Thus, as constitutional doctrine now stands, the state can only prohibit abortion outright (eliminating some methods such as "partial birth abortion" is another matter ${ }^{12}$ ) when the fetus is considered viable.

Unfortunately, the concept of viability itself remains subject to confusion. ${ }^{13}$ Like the Supreme Court, our societal normative tendency has been to assign a cut-off for fetal viability based on estimation of gestational age alone; however, we now know that other factors such as sex, birth weight, and maternal exposure to steroids affect probabilities of long-term neonatal survival. ${ }^{14}$ Other things being equal, extremely premature female newborns generally have better survival odds than their male counterparts. More importantly, clinical definitions of viability reflect a complex amalgam of prevailing medical and socio-cultural attitudes of a particular society; thus, in the U.S. and the U.K., few neonates are resuscitated below 23 weeks gestation by LMP, whereas in the Netherlands, that age rises to 25 by LMP. ${ }^{15}$ By contrast, in Japan, more neonates born above 22 weeks by LMP are resuscitated. ${ }^{16}$ Regardless of threshold, because in aggregate so few neonates are resuscitated at or near 20 weeks "postfertilization" anywhere in the world (22 weeks by LMP), we do not really know how many of those extremely immature neonates could survive. ${ }^{17}$ The most reliable available published data suggests a survival to discharge range between $1 \%$ and $20 \%{ }^{18}$

Working clinical definitions of viability involve human interpretation of statistical probabilities that are typically applied to a class of about-to-be-born fetuses. That is, they are not individual patient-specific, and as such, also likely (and in some cases subconsciously) represent a collective consensus about scarce resource allocation. As our chances of success diminish, it becomes less compelling to offer an intervention. Longterm survival data alone is not all that informs collective viability thresholds; a heavy majority of survivors born below 23 weeks gestation by LMP will sustain significant permanent cognitive and physical disabilities and this no doubt affects our interpretation of where to draw the line.

The fact that different viability thresholds exist in different regions of the world let alone different regions within the United States suggests that conscientious people might reasonably disagree about what percentage chance of survival (with or without long-term disabilities) is sufficient to warrant an attempt at newborn rescue. Put differently, given what data we possess on mortality and morbidity for extremely premature neonates, few obstetricians or neonatologists would advocate that we create a uniform policy of attempting resuscitation on every fetus born at or above 20 weeks postfertilization (using the Nebraska statutory language).

In the abortion context, we suggest that legislative attention on viability potentiates a false sense of "fetal security" which can be illustrated by putting the new Nebraska law into operation. Imagine two pregnant women at an Omaha clinic who both desire an abortion but who do not qualify for the highly restrictive medical emergency exception. Both women are determined by LMP to carry fetuses at 22 weeks and five days with a reasonable margin of error of plus or minus five days (note: even this degree of precision is often not available). Both women are told the provider is outlawed from performing the procedure. The first women leaves discouraged. The second woman, after the shock of hearing the news, goes into active, uncontrollable labor and within an hour 
proceeds to deliver an extremely premature newborn. The woman decides the best thing for her child, given such long odds, is to direct care toward maximizing comfort and ensuring dignity during the dying process. This palliative choice is respected by her providers because in the U.S. pediatrics community, there is generally consensus that neonates born below 23 weeks by LMP should not be resuscitated given their poor chance of survival without significant disability.

We highlight this clinically asymmetric outcome to emphasize that legally constructed thresholds of viability, while in the Supreme Court's mind the only "workable" solution, should not be mistaken to ensure some absolute protection for about-to-be born fetuses. In practice, fetuses that cannot lawfully be aborted because they have just barely crossed a legislatively determined definition of viability are routinely and intentionally allowed to die shortly after birth despite having a small statistical chance of survival. At least theoretically, this does provide a loophole (albeit unattractive, much like back alleys) for pregnant women, who cannot obtain an abortion at or beyond 20 weeks post-fertilization but who also do not desire to have a child, to self-induce extremely premature labor and only present to the hospital when it is beyond the point of controlling and immediate delivery is required.

The normative question that logically follows from the law's continued endorsement of viability as the basic trigger for restricting a woman's abortion right is whether we then ought to restrict parental liberty to refuse potentially life-sustaining therapy (or provider discretion to offer the same) for a baby born who is possibly viable based on the legislative definition. Nothing is mentioned in the Nebraska law about potential obligations of physicians poised to attempt a neonatal resuscitation in cases of birth at or just after 20 weeks postfertilization ( 22 weeks by LMP). The statute does, however, discourage any prenatal actions that have "an intention other than to increase the probability of a live birth," or "to preserve the life or health of the child after live birth." ${ }^{, 19}$

\section{The State's New Interest in Preventing Fetal Pain}

Although the Supreme Court has said that the preservation of fetal life becomes compelling only at the viability point, it has not said this can be the state's only compelling interest and it has said nothing about fetal pain at all. Nebraska appears to have capitalized on this gap and in its statute declares:

It is the purpose of the State of Nebraska to assert a compelling state interest in protecting the lives of unborn children from the stage at which substantial medical evidence indicates that they are capable of feeling pain. ${ }^{20}$

In so doing it has set up a novel legal question: is an abortion prohibition premised on preventing fetal pain constitutional? By drawing a line at 20 weeks postfertilization age, the Nebraska statute rather conveniently presents this question as to a fetus with a presumptive low probability yet some possibility of viability. However, we note that the statute appears to assert a compelling state interest in preventing pain that could permit 
the state to ban abortions of fetuses even if there is no chance of viability. Is this move constitutional?

There are at least two variants of the argument one might construct for the Nebraska statute's constitutionality: (1) the prevention of pain in itself is a compelling state interest sufficient to allow the state to prohibit abortion at any stage where the fetus will feel pain (call this the "pain standing-alone argument"); (2) while preserving fetal life is not a compelling state interest until the viability point, the state's interest in preserving fetal life of a not-yet-viable fetus becomes compelling when we add the prevention of fetal pain on to it, thus two state interests not compelling standing alone may be compelling when added together (call this the "combination argument"). We focus on the latter because it is stronger. Both of these arguments are to be contrasted with an argument that would seek to use fetal pain to limit the types of abortion one can perform on already-viable fetuses, such as "partial birth abortion" bans.

The Nebraska statute might be read as offering as its constitutional ground either the "pain standing-alone" or "combination" argument. An earlier draft of the legislation more strongly suggested the pain standing-alone argument, with a now-omitted legislative finding that " $[\mathrm{t}]$ here is a valid state interest in reducing or preventing events in which pain is inflicted on sentient and nonsentient creatures. Examples of laws that serve this interest are laws governing the use of laboratory animals, laws requiring pain-free methods of slaughtering livestock, and laws regarding hunting methods on federal lands." 21 Thus, as originally drafted, rather than carving out a special exception for preventing human fetal pain, the statute explicitly compared it to the pain felt by other "sentient creatures.",22

This version of the argument may be susceptible to the objection that it proves too much. Its logic suggests that the government should also be able to outlaw all forms of hunting, all forms of not-painless animal experimentation, and all forms of animal consumption that do not involve painless methods. To the extent one might claim any of those activities were protected by a fundamental substantive Due Process constitutional right, on the rationale of the Nebraska statute those rights too are defeated by the state's compelling interest in pain-prevention. If any of those activities were protected by something less than a fundamental right, as seems plausible, then the conclusion follows a fortiori if the pain standing alone argument is correct. That is, if the prevention of pain to a sentient creature is enough to justify infringing on what is avowedly a fundamental right of women to have an abortion, it should plausibly justify infringing on a right receiving less constitutional protection. Because the structure of this objection to this version of the argument is a reductio ad absurdum, its force depends on the absurdity of the conclusion to which the argument leads; that is, if one thought that the state could in fact consistent with the Constitution outlaw all forms of hunting, all forms of not-painless animal experimentation, and all forms of animal consumption that do not involve painless methods, then this implication of the pain standing alone argument should not be troublesome. If, however, the constitutionality of those kinds of hypothetical laws seems implausible, so should the pain standing-alone argument.

In any event, the more sophisticated version of the argument - the combination argument - sidesteps this objection altogether, because it does not claim that preventing any pain to sentient creatures qualifies as a compelling state interest sufficient to trump an existing fundamental right, but instead, only pain to human fetuses in whom the state 
has a growing but not-yet compelling state interest before viability. One could also sidestep this objection by offering a reconstruction of the pain standing-alone argument that sought to limit itself to fetal pain but did not attempt to combine the argument with the state's pre-viability interest in preserving fetal life, call this the "fetal pain standingalone" argument. Such a reconstruction would have to show why pain to human beings, standing alone, mattered from a constitutional vantage point while pain to non-human animals did not. We do not dwell on this possible reconstruction because we think it is less persuasive than the combination argument and, in any event, all of the arguments we now offer against the combination argument apply equally well to it.

As a reason to uphold the Nebraska statute as constitutional, we think the more sophisticated combination argument is problematic for at least three reasons:

First, the available scientific evidence to date does not support the Nebraska legislature's claim that "substantial medical evidence" could support a conclusion that fetuses at 20 weeks postfertilzation age are "capable of feeling pain." 23 Indeed, the best available evidence remains a systematic multidisciplinary review published in JAMA in 2005, in which the authors conclude:

Pain is an emotional and psychological experience that requires conscious recognition of a noxious stimulus. Consequently, the capacity for conscious perception of pain can arise only after thalamocortical pathways begin to function, which may occur in the third trimester around 29 to 30 weeks' gestational age, based on the limited data available. Small-scale histological studies of human fetuses have found that thalamocortical fibers begin to form between 23 and 30 weeks' gestational age, but these studies did not specifically examine thalamocortical pathways active in pain perception. While the presence of thalamocortical fibers is necessary for pain perception, their mere presence is insufficient - this pathway must also be functional. It has been proposed that transient, functional thalamocortical circuits may form via subplate neurons around midgestation, but no human study has demonstrated this early functionality. ${ }^{24}$

Importantly, no new revelatory scientific insights have been published since 2005 to challenge the authors' findings at the time. ${ }^{25}$ Thus, while it may be accurate for Nebraska to find that some of the anatomic structures within the developing nervous system are present in a normally developed fetus at 20 weeks postfertilization gestation, it is misleading to suggest this physical reality is sufficient for a fetus to "experience" pain. It is further misleading to suggest that observable neuroendocrine, metabolic, and reflexive responses to stimuli are equivalent to meaningful pain perception. Each of these later responses can be elicited even in the absence of nociception and none require consciousness. $^{26}$

To avoid both a tautological misstep and clinical tomfoolery, experts on pain physiology agree that subjective experience is necessary for any definition of pain, and they distinguish nociception from the personal experience of pain. ${ }^{27}$ In clinical terms, it is difficult to see a benefit in giving morphine to a patient who happily and honestly tells us with a smile on her face that she feels no pain despite us also recognizing that some of 
her neuro-sensory pathways are being stimulated by our procedure. This remains true even if the patient is in the dying process.

Second, if the presence of fetal pain is what causes the state's interest to become compelling, then if that pain can be prevented the interest should cease to carry much, if any, weight. Given that there are good reasons to doubt whether borderline viable fetuses possess anything beyond basic nociception, it is not surprising that we have little evidence to support any kind of routine practice regarding optimal fetal analgesia. Nebraska legislators engage in faulty inferential thinking when they rely on findings that "[a]nesthesia is routinely administered to unborn children who have developed twenty weeks or more past fertilization who undergo prenatal surgery" and that "hormonal stress responses to painful stimuli [exhibited by unborn children] were reduced when pain medication was administered directly to such unborn children" as further evidence that fetuses feel pain. ${ }^{28}$ In 2001, an authoritative textbook on fetal surgical therapy stated that the need for and "benefit of fetal anesthesia" during operative procedures performed in utero "has not been documented." ${ }^{, 29}$ Similarly, the 2005 JAMA review co-authored by a leading expert on fetal anesthesia notes:

Surgical procedures undertaken for fetal benefit use anesthesia to achieve objectives unrelated to pain control, such as uterine relaxation, fetal immobilization, and possible prevention of neuroendocrine stress responses associated with poor surgical outcomes. Thus, fetal anesthesia may be medically indicated for fetal surgery regardless of whether fetal pain exists. ${ }^{30}$

Still, even if we assume for argument's sake, that a pre-viable fetus' potential capacity for nociception carries any risk of conscious pain perception, there is no reason to question that this sensory experience could be sufficiently and adequately blunted with the appropriate use of standard narcotic analgesics, just as it is done every day in thousands of operating rooms around the United States with infants, children, and adults undergoing surgical procedures. That abortion providers have historically not thought to provide fetal analgesia (for the defensible reasons discussed above) does not mean they could not do so in the future if abortion remains a constitutionally protected right. To put this point in constitutional law parlance, ${ }^{31}$ the Nebraska statute is not narrowly tailored to the (purported) compelling state interest in preventing pain if it also outlaws abortions where such pain can be prevented. This alone seems constitutionally fatal.

Perhaps one might respond that we are subtly misconstruing the statute, that the bill's title suggests what Nebraska is claiming is that the capacity to feel pain is itself a criterion of constitutional personhood, such that pain-capable fetuses are constitutional persons. A similar claim has on occasion been made as a theory of personhood from an ethical standpoint, at least as to some rights associated with personhood. ${ }^{32}$ Such an approach would suggest that a fetus' capacity to feel pain at a given age should render it protected from abortion whether or not it actually feels pain in the abortion process; to put the point another way, to say that pain-capable fetuses deserve constitutional personhood is roughly equivalent to saying that the state has a compelling interest in preventing the termination of pain-capable fetuses before viability, whether or not those fetuses actually experience pain through the abortion procedure. Shifting to the capacity to feel pain as the constitutionally relevant fact would enable defenders of the statute to 
escape our point about fetal analgesics, for even if the fetus will actually feel no pain during the abortion, it is its status as a pain-capable entity that renders the abortion problematic. However, this defense of the statute also comes at a cost: it threatens to return us to the reductio discussed above in that it would also suggest that animals who can feel pain should also qualify for constitutional personhood at least as to being killed, unless one could offer a constitutionally relevant "non-speciesist" (to use Peter Singer's term) ${ }^{33}$ further distinction between fetuses and animals. This argument would also require breaking with prior Supreme Court precedent suggesting that only at the viability point does the state's interest in the preservation of fetal life become compelling. In any event, even if defenders of the Nebraska statute (or future legislatures) were to adopt this approach, it would leave intact our other two critiques of the statute.

Third, and finally, even if fetal pain is both real and unavoidable, it is not clear that fetal pain should get the constitutional weight the Nebraska statute purports to attach to it. The claim of the argument is that prevention of pain to a legal non-person is enough when added to the state's interest in the preservation of fetal life to outweigh a woman's "right not to be a gestational parent" stemming from the protection of bodily integrity. ${ }^{34}$

As we have noted, as a pure doctrinal matter the Supreme Court has yet to address whether the state's interest in preventing fetal pain in combination with its interest in preserving the life of a not-yet-viable fetus constitutes a compelling state interest capable of overcoming a woman's fundamental right(s) protected by free abortion. Thus, we emphasize, the Supreme Court could uphold the Nebraska statute on this ground without having to explicitly overrule prior precedent. Still, to the extent that determination will in part depend on a normative analysis of the conflicting interests, there is good reason to think that while fetal pain may be relevant, it ought not to be dispositive on the issue.

Of course, there are many normative theories of the abortion right, some of which view it more as a balancing approach to moral values in conflict while others view it as an aspect of one's right to bodily integrity, and we do not purport to examine what each would say about fetal pain. Instead, we concentrate on one particularly influential defense of the abortion right offered by Judith Jarvis Thomson. ${ }^{35}$

Thomson offers a famous hypothetical meant to elicit the view that the right not to be a gestational parent — that is, the abortion right — ought to attach even if we granted fetal personhood. She asks us to imagine a woman who finds herself attached (though no fault of her own) to a famous violinist as a human dialysis machine, and is told that if she disconnects herself before the end of nine months, the violinist will die. ${ }^{36}$ If we think the woman has the right to "disconnect" herself, then that suggests that abortion ought to be lawful even if a fetus is a person, since the violinist is no doubt a person.

Now imagine we make explicit what might be thought implicit in Thomson's hypothetical: the violinist will suffer significant pain due to the disconnection. Does it make a difference as to our view of whether the woman may disconnect herself, as compared to the case where disconnection will result in the violinist's painless death? If it is not dispositive, then this once again suggests that the addition of fetal pain should not automatically trump the exercise of a woman's abortion rights, even for those who think fetuses are persons.

Extending Thomson's thought experiment can usefully distinguish the permissibility of considering fetal pain as a reason to make illegal certain types of abortion rather than to prohibit abortions altogether. If there existed two ways of 
detaching the violinist, one excrutiatingly painful to him and one painless, the state might be justified in allowing only the painless method even if that method imposed some burdens on the woman seeking to disconnect (exactly how much of a burden, being, of course, contentious). That conclusion does not, however, tell us that the presence of fetal pain is dispositive as to the question of whether the woman can disconnect at all. It is our (admittedly rebuttable) claim that most of us share the intuition that the individual should have the disconnect right in such a case even if it causes pain.

Some object to Thomson's argument that unlike for the violinist, the woman bears responsibility for her fetus - presuming she engaged in consensual sexual intercourse and that this ought to alter our reckoning of her moral (and perhaps legal) duties, while

others disagree.$^{37}$ For present purposes, resolving this dispute is of secondary importance; what matters is seeing that whichever way one resolves the dispute adding the additional fact of pain does not force a conclusion.

In conclusion, the Nebraska statute seems designed to target an open question in American constitutional jurisprudence: whether the presence of fetal pain can (standing alone or in combination with other interests) constitute a compelling state interest justifying prohibitions on abortion before viability. We have tried to construct the most favorable arguments for upholding the constitutionality of the Nebraska statute and subject them to careful examination. While we have concluded that the statute fails to meet that challenge and should be found unconstitutional, we think that the question is closer than defenders of the abortion right might like. More generally, we believe that there are genuine grounds to debate the extent to which and why the willful destruction of biological organisms (human or otherwise) should or should not be legal, and public debate oftentimes amplifies deeply held disagreements about which social, cultural, and religious values people think ought to be prioritized. While the Nebraska statute may have the more narrow aim of tempting predisposed federal judges to disregard Roe and other settled precedent, we hope that our reflections on the statute's constitutionality and normative justifiability can help further the larger debate in more measured and nuanced terms.

\section{Acknowledgements}

Thanks to B. Jessie Hill, Michelle Meyer, John Robertson, Benjamin Sachs, Mark Tushnet, and an anonymous reviewer for helpful comments.

1. Leg. Bill. $1103 \S 1(5), 5$ (Neb. 2010), available at $<$ nebraskalegislature.gov/FloorDocs/101/PDF/Slip/LB1103.pdf> (last visited March 4, 2011). The act defines "fertilization" as "the fusion of a human spermatozoon with a human ovum." Id., at $\S 1(3)$.

2. On February 24, 2011, Kansas' House approved its own fetal pain law, with a vote in the senate still pending. John Hanna, Kansas House Approves Nebraska-style Fetal Pain Abortion Bill, Associated PRESS, February 24, 2011.

3. Leg. Bill. 1103 § 1(5), 5 (Neb. 2010), available at $<$ nebraskalegislature.gov/FloorDocs/101/PDF/Slip/LB1103.pdf> (last visited March 4, 
2011). The act defines "fertilization" as "the fusion of a human spermatozoon with a human ovum." Id., at $§ 1(3)$.

4. Id. $\S 1$ The use of "postfertilization" in the legislation is curious and at odds with clinical practice. Arguably, it connotes a sense of accuracy that is absent in obstetrics. Traditionally, physicians estimate the gestational age of fetus based on the last menstrual period (LMP) of the pregnant woman. Conception is assumed to occur between 11 and 21 days after the first day of the LMP. The standard estimated gestational age by LMP, then, typically includes two "extra" weeks prior to actual fertilization. In this paper,we move back and forth between LMP and postfertilization when referring to gestational age. References to postfertilization gestational age are definitionally two weeks less than references to gestational age calculated by LMP (e.g., 20 weeks postfertilization equals 22 weeks by LMP).

5. Id. at $\S 5$.

6. In the Partial Birth Abortion Act of 2003, 18 U.S.C. $\S 1531$ (2006), among the Congressional findings accompanying the law were:

The vast majority of babies killed during partial-birth abortions are alive until the end of the procedure. It is a medical fact, however, that unborn infants at this stage can feel pain when subjected to painful stimuli and that their perception of this pain is even more intense than that of newborn infants and older children when subjected to the same stimuli. Thus, during a partial-birth abortion procedure, the child will fully experience the pain associated with piercing his or her skull and sucking out his or her brain.

Finding 14(m). See also J. Miller, "Understanding Fetal Pain: How Changes

Circumstances Demand a Legal Response," Cumberland Law Review 40, no. 2 (20092010): 463-497, at 477. The act was upheld in Gonzales v. Carhart, 550 U.S. 124 (2007), but without discussion of fetal pain.

7. It also differs from legislation introduced in several states that require physicians to inform patients seeking abortion that there is the possibility that fetuses feel pain. See H. Tobin, "Confronting Misinformation on Abortion: Informed Consent, Deference and Fetal Pain," Columbia Journal of Gender \& Law 17, no. 1 (2008): 111-152, at 113-114.

8. Roe v. Wade, 410 U.S. 113, 163-64 (1973).

9. City of Akron v. Akron Ctr. for Reprod. Health, Inc., 462 U.S. 416, 457-458 (1983)

(O'Connor, J., dissenting).

10. Planned Parenthood of Se. Pa.v. Casey, 505 U.S. 833, 860 (1992) (plurality).

11. Id.

12. Carhart, 550 U.S. at 124.

13. S. Sayeed, "The Problem of Non-Identity in Valuing Newborn Human Life," Georgia State Law Review 25, no. 4 (2009): 865-899.

14. J. Tyson et al., "Intensive Care for Extreme Prematurity - Moving Beyond Gestational Age," New England Journal of Medicine 358, no. 16 (2008): 1672-1681.

15. S. Verloove-Vanhorick, "Management of the Neonate at the Limits of Viability: The Dutch Viewpoint," BJOG 113, Supp. 3 (December 2006): 13-16. American Heart Association, and American Academy of Pediatrics, "2005 American Heart Association (AHA) Guidelines for Cardiopulmonary Resuscitation (CPR) and Emergency 
Cardiovascular Care (ECC) of Pediatric and Neonatal Patients: Neonatal Resuscitation Guidelines," Pediatrics 117, no. 5 (May 2006): e1029-e1038.

16. S. Kusuda, M. Fujimura, I. Sakuma, H. Aotani, K. Kabe, Y. Itani, H. Ichiba, K. Matsunami, H. Nishida, Neonatal Research Network, Japan, "Morbidity and Mortality of Infants with Very Low Birth Weight in Japan: Center Variation," Pediatrics 118, no. 4 (October 2006): e1130-e1138.

17. See Sayeed, supra note 13, at 856-899; J. A. Lemons, C. R. Bauer, W. Oh, S. B. Korones, L. A. Papile, B. J. Stoll, J. Verter, M. Temprosa, L. L. Wright, R. A. Ehrenkranz, A. A. Fanaroff, A. Stark, W. Carlo, J. E. Tyson, E. F. Donovan, S. Shankaran, and D. K. Stevenson, "Very Low Birth Weight Outcomes of the National Institute of Child Health and Human Development Neonatal Research Network, January 1995 through December 1996. NICHD Neonatal Research Network," Pediatrics 107, no. 1 (January 2001): E1.

18. See Kusuda, supra note 16; N. S. Wood, N. Marlow, K. Costeloe, A. T. Gibson, and A. R. Wilkinson, "Neurologic and Developmental Disability after Extremely Preterm Birth. EPICure Study Group," New England Journal of Medicine 343, no. 6 (2000): 378384.

19. Leg. Bill. $1103 \S 2(1)$.

20. Id., at $\S 5$.

21. Leg. Bill. $1103 \S 3(6)$ (Neb. Jan. 1, 2010) (First Reading Version), available at $<$ nebraskalegislature.gov/FloorDocs/101/PDF/Intro/LB1103.pdf > (last visited March 4, 2011). All other references to the bill are to the version that was actually enacted. 22. Given that "nonsentient" creatures do not feel pain, the reference to pain to nonsentient creatures in the earlier version of the statute is mysterious.

23. Leg. Bill. 1103, at $\S 5$.

24. S. Lee et al., "Fetal Pain: A Systematic Multidisciplinary Review of the Available Evidence," JAMA 294 (8) (2005): 947-954.

25. S. Derbyshire, "Fetal Pain: Do We Know Enough to Do the Right Thing?"

Reproductive Health Matters 16, no. 31, Supp. (2008): 117-126.

26. See also Tobin, supra note 7, at 147-151 (reviewing existing evidence for claim that fetuses feel pain at 20 weeks gestation and declaring them "questionable on the issue of truthfulness, and [] misleading."). For these reasons we are skeptical of the medical claim that fetuses feel pain and think it poorly factually grounded. As a matter of doctrinal constitutional law, however, it is at least possible that the Roberts court may defer to Nebraska's legislative findings on this issue despite their poor factual foundations. In two of its recent abortion decisions, the Court has sent mixed signals on deference to legislative findings in the abortion context. In Stenberg v. Carhart, 530 U.S. 914 (2000), the majority did not mention deference while the dissent chastised the majority for failing to afford the legislature deference; see id., at 1017 (Thomas, J. Dissenting); id., at 967970 (Kennedy, J., dissenting); see Tobin, supra note 7, at 132-134. More recently, in Gonzales v. Carhart, speaking to the question of a possible health exception the majority suggested no deference, writing: "Although we review congressional factfinding under a deferential standard, we do not in the circumstances here place dispositive weight on Congress' findings[; t ] he Court retains an independent constitutional duty to review factual findings where constitutional rights are at stake," suggesting that "some 
recitations in the Act are factually incorrect" and that "uncritical deference to Congress' factual findings in these cases is inappropriate." 550 U.S. 124, 165-66 (2007). The Court is far from pellucid as to what it means by "in the circumstances here" and "in these cases," and the same opinion also offers some cues in the other direction. See Tobin, supra note 7, at 133-134. Thus, while deference seems less likely given these precedents the matter is far from resolved.

27. International Association for the Study of Pain, "IASP Pain Terminology," 2004. available at http://www.iasp-

pain.org/AM/Template.cfm?Section=Pain_Definitions\&Template=/CM/HTMLDisplay.c

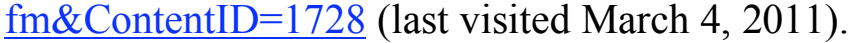

28. Leg. Bill. 1103, at $\S 5$.

29. M. Harrison, M. Evans, N. Adzick, and W. Holzgreve, The Unborn Patient: The Art and Science of Fetal Therapy (Philadelphia: W.B. Saunders Co., 2001).

30. See Lee, supra note 24. As these authors put it in their JAMA article at p. 951:

When long-term fetal well-being is a central consideration, evidence of fetal pain is unnecessary to justify fetal anesthesia and analgesia because they serve other purposes unrelated to pain reduction, including (1) inhibiting fetal movement during a procedure; (2) achieving uterine atony to improve surgical access to the fetus and to prevent contractions and placental separation; (3) preventing hormonal stress responses associated with poor surgical outcomes in neonates; and (4) preventing possible adverse effects on long-term neurodevelopment and behavioral responses to pain. These objectives are not applicable to abortions.. Id., at 181; see also Tobin, supra note 7, at 147.

32. Casey, 505 U.S. at 935.

33. See, e.g., P. Singer, Animal Liberation (New York: Random House, 1975).

34. I. G. Cohen, "The Constitution and the Rights Not to Procreate," Stanford Law Review 60, no. 4 (2008): 1135-1196. Under the version of the "combination" argument we have been discussing, it is pain to a human fetus coupled with the state's growing but not-yet compelling state interest before viability that in combination constitutes a compelling state interest that overcomes the woman's abortion right claim. We have settled on that variant because it is the most favorable to the Nebraska law, but, inspired by the pain standing alone argument, one could also imagine a less plausible variant that treats pain to all sentient beings alike in terms of the "combination." Where might the two versions diverge? Imagine that the only way to perform an abortion at 20 weeks postfertilization age was to inject into a woman serum from a chicken brain that could only be gathered by subjecting the chicken to excruciating pain, but which would be painless for the woman's fetus. Under this less plausible version of the combination argument, the state should be able to prohibit the abortion because of its interest in preventing pain to a non-person capable of feeling it (the chicken) in combination with its desire to preserve fetal life (of the fetus). On the one hand, that result seems strange, and it seems hard to imagine the Supreme Court upholding such a prohibition. On the other hand, one might ask: why should the constitutional status of the abortion act change just because it is the same entity to whom we want to prevent pain and preserve life? One answer might be that fetal pain "counts" more because its victim is human, but again one 
might worry that the reason why is "speciesism" of the kind decried by Singer, supra note 33 .

35. Thus, it is possible that on some of these other theories the presence or absence of fetal pain might be more relevant to the permissibility of abortion.

36. J. J. Thomson, "A Defense of Abortion," Philosophy and Public Affairs 1, no. 1 (1971): 47-67.

37. Thomson herself discusses these issues. Id. at 58-65. 